\title{
A genetic risk tool for obesity predisposition assessment and personalized nutrition implementation based on macronutrient intake
}

\author{
Leticia Goni · Marta Cuervo · Fermín I. Milagro • \\ J. Alfredo Martínez
}

Received: 15 April 2014/ Accepted: 19 November 2014/Published online: 28 November 2014

(C) Springer-Verlag Berlin Heidelberg 2014

\begin{abstract}
There is little evidence about genetic risk score (GRS)-diet interactions in order to provide personalized nutrition based on the genotype. The aim of the study was to assess the value of a GRS on obesity prediction and to further evaluate the interactions between the GRS and dietary intake on obesity. A total of 711 seekers of a Nutrigenetic Service were examined for anthropometric and body composition measurements and also for dietary habits and physical activity. Oral epithelial cells were collected for the identification of 16 SNPs (related with obesity or lipid metabolism) using DNA zip-coded beads. Genotypes were coded as 0,1 or 2 according to the number of risk alleles, and the GRS was calculated by adding risk alleles with such a criterion. After being adjusted for gender, age, physical activity and energy intake, the GRS demonstrated that individuals carrying $>7$ risk alleles had in average $0.93 \mathrm{~kg} / \mathrm{m}^{2}$ of BMI, $1.69 \%$ of body fat mass, $1.94 \mathrm{~cm}$ of waist circumference and 0.01 waist-to-height ratio more than the individuals with $\leq 7$ risk alleles. Significant interactions for GRS and the consumption of energy, total
\end{abstract}

Electronic supplementary material The online version of this article (doi:10.1007/s12263-014-0445-z) contains supplementary material, which is available to authorized users.

L. Goni · M. Cuervo · F. I. Milagro - J. A. Martínez $(\bowtie)$

Department of Nutrition, Food Sciences and Physiology, University of Navarra, Irunlarrea, 1, 31008 Pamplona, Spain e-mail: jalfmtz@unav.es

L. Goni · M. Cuervo · F. I. Milagro · J. A. Martínez

Centre for Nutrition Research, University of Navarra, Irunlarrea,

1, 31008 Pamplona, Spain

M. Cuervo · F. I. Milagro - J. A. Martínez CIBER Fisiopatología de la Obesidad y Nutrición (CIBERobn), Instituto de Salud Carlos III, Madrid, Spain protein, animal protein, vegetable protein, total fat, saturated fatty acids, polyunsaturated fatty acids, total carbohydrates, complex carbohydrates and fiber intake on adiposity traits were found after adjusted for confounders variables. The GRS confirmed that the high genetic risk group showed greater values of adiposity than the low risk group and demonstrated that macronutrient intake modifies the GRS association with adiposity traits.

Keywords Genetic risk score - Obesity · Adiposity · Gene-macronutrient interaction

\section{Introduction}

The prevalence of obesity is rising steadily not only in high-income countries but also in low-income countries. Indeed, it has been estimated that 1.12 billion adults will be obese by 2030 (Kelly et al. 2008). Consequently, the prevalence of obesity-associated metabolic diseases, such as type 2 diabetes, cardiovascular disease or certain cancers, will also increase (Wang et al. 2011).

Although obesity is generally attributed to an imbalance between the energy intake and the energy expenditure, heritability studies indicate that genetic factors also play an important role in energy metabolism and the susceptibility to obesity (Abete et al. 2010; Min et al. 2013). Indeed, genome-wide association studies (GWAS) have identified a large number of single nucleotide polymorphisms (SNPs) associated with obesity and metabolic-related traits, which later have been widely replicated in different populations (Fall and Ingelsson 2014; Lind and Chiu 2013; Qi and Hu 2012; Global Lipids Genetics Consortium et al. 2013). Previous simulation studies have shown that the predictive value of a genetic variant could be improved by combining 
multiple loci simultaneously in a genetic risk score (GRS) model (Moonesinghe et al. 2010). In fact, (Belsky et al. 2013) concluded that a 32 obesity locus GRS is a good predictor of body mass index (BMI) and obesity among Caucasians. Although it has been reported the discriminative and predictive power of GRSs of obesity SNPs, to the best of our knowledge, no study so far has specifically evaluated a multi-trait GRS of both, obesity and lipid metabolism SNPs (San-Cristobal et al. 2013).

Genetic factors could account for $25-70 \%$ of the body weight inter-individual variability (Razquin et al. 2011). Thus, genetic variants alone seem to be insufficient to explain the obesity heritability. In this context, a large number of investigations have suggested several interactions between certain genetic polymorphisms and modifiable environmental factors such as dietary intake or physical activity (Qi 2014; Roth et al. 2012). Nevertheless, there is scarce information regarding interactions between obesity GRSs and lifestyle factors. Interactions with physical activity (Li et al. 2010a; Ahmad et al. 2013), television watching (Qi et al. 2012a), meal frequencies (Jaaskelainen et al. 2013), omega-3 polyunsaturated fatty acids (PUFA) (Lemas et al. 2013), sugar-sweetened beverages (Qi et al. 2012b) and fried food (Qi et al. 2014) have been described, although other report could not observe any strong interactions with macronutrients (Rukh et al. 2013).

Thus, the two main aims of this study were to test the associations between a multi-trait GRS and body composition measurements and to further evaluate dietary intake and obesity interactions depending on the genotype.

\section{Materials and methods}

\section{Subjects}

The study population included men and women of Caucasian ancestry who voluntarily attended a Nutrigenetic Service located in community pharmacies in seven regions of Spain (Barcelona, Zaragoza, La Coruña, Pontevedra, Madrid, Granada and Málaga). Genotype information of 718 individuals was available. Of these, seven subjects were excluded with missing values for dietary intake, physical activity and/or anthropometric measurements. In total, 711 individuals were included in the analysis.

Seekers of the Nutrigenetic Service were specifically asked if they would be willing to take part anonymously in the research study. After ensuring that participants had understood the information, only those who provided written informed consent for participation were enrolled. The survey was in accordance with the principles of the Declaration of Helsinki and patient data were codified to guarantee anonymity accuracy (World Medical Association 2013). The Research Ethics Committee of the University of Navarra gave confirmation of fulfillment of the ethical standards and deontological criteria affecting this research (ref. 2710/2014).

\section{Data collection}

Anthropometric measurements were collected by trained nutritionists using a standardized protocol. Individuals were weighed with a digital scale (TANITA BF522W), wearing light clothes and no shoes. Height was measured using a portable stadiometer (Leicester TANITA) with subjects in barefoot. BMI was calculated dividing weight $(\mathrm{kg})$ by the square of height (m). Body fat mass (BFM) was determined by bioelectrical impedance using the TANITA BF522W. Body fat distribution was evaluated by the measurement of waist and hip circumferences using a flexible and inextensible tape measure. Waist circumference was measured at the midway between the lower margin of the least rib and the top of iliac crest or according to the circumference at the level of the umbilicus if it was not possible to identify the least rib or the iliac crest; and hip circumference as the widest circumference over the greater buttocks. Waist-to-hip ratio (waist/hip) and waist-to-height ratio (waist/height) were then calculated.

Physical activity was determined using a short 24-h physical activity questionnaire (Panel on Macronutrients et al. 2005). Subjects were asked about the number of hours resting and practicing activities at work or at leisure time during a week day and a weekend day. Activities were divided in four groups according to intensity of effort: sedentary, low active, active and very active. Individual daily physical activity level was calculated multiplying the average time spent on each group of activities during the week and the weekend and the multiples of physical activity levels (Panel on Macronutrients et al. 2005).

Diet information was collected by a food frequency questionnaire in which basic foods were classified into 19 food groups: whole dairy products, half-fat dairy products and fat-free dairy products, eggs, fat meat and sausages, lean meat, white fish and shellfish, blue fish, vegetables, fruits, nuts, legumes, olive oil, other fats and oils, refined grains, whole grains, pastries and confectionary industry, sugars, water and alcohol drinks. Each food group comprised several foods based on a food exchange list system (de la Iglesia et al. 2014). In other words, the foods on each group have about the same amount of calories, carbohydrate, protein and fat. For example, the group of whole dairy products (in average $67.6 \mathrm{kcal}, 3.9 \mathrm{~g}$ carbohydrate, $4.2 \mathrm{~g}$ protein and $4.0 \mathrm{~g}$ fat) comprised $125 \mathrm{ml}$ of milk, $50 \mathrm{~g}$ of milk powder, $125 \mathrm{~g}$ of different types of yogurt and $50 \mathrm{~g}$ of fresh cheese. Subjects were asked to report how often 
(daily, weekly, monthly or never) they had consumed a choice of each food group during the previous year. Total energy intake and macronutrient composition were calculated using Spanish food composition tables (Mataix et al. 2009; Moreiras et al. 2012).

\section{Genetic risk score (GRS)}

This research was based on a genetic tool developed by a pharmaceutical company (CINFA) which comprised 23 polymorphisms related with nutrition. Of the 23 SNPs, a total of 16 SNPs previously associated with obesity and lipid metabolism on the basis of published reports were selected. Of these, rs9939609 and rs17782313, which represent the obesity susceptibility loci in the FTO and $M C 4 R$ genes, respectively, have been identified by GWAS (Frayling et al. 2007; Willer et al. 2009; Loos et al. 2008). A recent meta-analysis has confirmed the association between the genetic variant rs1801282 (PPARG) and BMI (Galbete et al. 2013a). The polymorphisms rs1801133 (MTHFR) and rs894160 (PLIN1) have been related with obesity phenotype in some association studies (Lewis et al. 2008; Soenen et al. 2009). Seven polymorphisms, rs1260326 (GCKR), rs662799 (APOA5), rs4939833 (LIPG), rs1800588 (LIPC), rs328 (LPL), rs12740374 (CELSR2) and rs7412 (APOE), have been reported to be associated with some lipid metabolism disturbances (hypertriglyceridemia, hypercholesterolemia, high lowdensity lipoprotein-LDL-levels or low high-density lipoprotein-HDL-levels) by GWAS (Willer et al. 2008; Kathiresan et al. 2008; Sandhu et al. 2008; Kettunen et al. 2012). The SNP rs429358 (APOE) has been associated with some lipid metabolism disorders by a meta-analysis of association studies (Bennet et al. 2007); and three SNPs, rs1799983 (NOS3), rs1800777 (CETP) and rs1800206 (PPARA), by association studies (Ferguson et al. 2010; Chrysohoou et al. 2004; Lu et al. 2008; Tai et al. 2002).

The GRS was calculated assuming that each SNP acts independently and contributes equally to the risk of obesity in an additive manner, as has been previously reported (He et al. 2010; Peterson et al. 2011). Genotypes were coded as 0,1 or 2 according to the number of risk alleles for each variant. The GRS was computed by summing the risk alleles across the 16 SNPs for each individual.

\section{Genotyping}

Genomic DNA from oral epithelial cells (collected in ORAcollect DNA ${ }^{\circledR}$, DNAGenotek) was extracted by QIAcube using QiAmp DNA Mini QIAcube Kit (Qiagen), following the manufacturer procedures. The polymerase chain reactions were carried out using the GeneAmp ${ }^{\circledR}$ PCR System 9700 thermal cycler according to standardized laboratory protocols. PCR products were analyzed using Luminex ${ }^{\circledR} 100 / 200^{\mathrm{TM}}$ System, which is based on the principles of $\mathrm{xMAP}^{\circledR}$ Technology. Briefly, this method uncompressed polystyrene microspheres internally dyed with various ratios of spectrally distinct fluorophores, which are detected by a flow cytometry-based instrument (Dunbar 2006).

\section{Statistical analysis}

Deviation from Hardy-Weinberg equilibrium was tested by $\chi^{2}$ test. Linear regression analyses (adjusted for age, sex, physical activity and total energy intake) were used to evaluate the association between the GRS or individual SNPs and body composition measurements (BMI, percentage of BFM, waist circumference, hip circumference, waist/hip and waist/height). Logistic regression analyses were applied to examine odds ratios of GRS for obesity (BMI $\geq 30 \mathrm{~kg} / \mathrm{m}^{2}$; percentage of $\mathrm{BFM}>25 \%$ for males and $>33 \%$ for females), and for risk of cardiovascular disease (waist circumference $>94 \mathrm{~cm}$ for males and $>80 \mathrm{~cm}$ for females; waist/hip $\geq 0.90$ for males and $\geq 0.85$ for females; waist/height $\geq 0.53$ for males and $\geq 0.51$ for females), after they were adjusted for age, sex, physical activity and total energy intake as confounder variables (Rubio et al. 2007; Sociedad Española para el Estudio de la Obesidad-SEEDO 2000; World Health Organization 2008). The discriminative power of the GRS was tested by the area under the receiver operating characteristic curves (ROC AUCs) (Dorfman and Alf 1969; Cleves 1999). Interactions between the GRS or SNPs and diet intake on percentage of BFM and obesity risk (according to the percentage of BFM) were examined with the likelihood ratio test (Sánchez-Villegas and Martínez-Gonzalez 2006). Product terms between the GRS or SNPs and diet intake were calculated with the nutrients dichotomized at the median and as continuous variables. All statistical analyses were performed using STATA/SE, version 12.0 (StataCorp, College Station, TX, USA). A $p$ value of $p<0.05$ was considered as statistically significant.

\section{Results}

The phenotypical characteristics of the individuals included in the study were categorized by gender (Table 1). As expected, males showed higher height, weight and waist circumference than females. In contrast, females had greater percentage of BFM. Energy intake and physical activity were higher in males than in females. Of the 711 subjects, $41.6 \%$ were obese, and no statistical differences were observed depending on gender. About $40.9 \%$ of the individuals self-declared that they suffered one or more 
Table 1 Anthropometrical and nutritional baseline characteristics stratified and statistically compared by gender

$B M I$ body mass index, $B F M$ body fat mass

${ }^{a}$ Chi-squared $p$ value

Table 2 Genotype, minor allele frequency (MAF) and Hardy-Weinberg equilibrium calculations of the 16 SNPs included in the GRS

SNP single nucleotide polymorphism, $M A F$ minor allele frequency, $H W E p$ value hardy-weinberg equilibrium $p$ value

${ }^{a}$ According to Hap-Map CEU for European population

\begin{tabular}{llllr}
\hline Variables & All $(n=711)$ & Males $(n=159)$ & Females $(n=552)$ & $p$ value \\
\hline Age $($ years $)$ & $50.1 \pm 13.4$ & $47.9 \pm 13.6$ & $50.7 \pm 13.2$ & 0.016 \\
Height $(\mathrm{cm})$ & $163.0 \pm 8.8$ & $173.7 \pm 7.5$ & $159.9 \pm 6.4$ & $<0.001$ \\
Weight $(\mathrm{kg})$ & $78.2 \pm 16.7$ & $90.0 \pm 16.4$ & $74.8 \pm 15.2$ & $<0.001$ \\
BMI $\left(\mathrm{kg} / \mathrm{m}^{2}\right)$ & $29.4 \pm 5.8$ & $29.8 \pm 5.0$ & $29.3 \pm 6.0$ & 0.339 \\
Obesity $\left(\mathrm{BMI} \geq 30 \mathrm{~kg} / \mathrm{m}^{2}\right)(\%)$ & $296(41.6)$ & $68(42.8)$ & $228(41.3)$ & $0.742^{\mathrm{a}}$ \\
BFM $(\%)$ & $34.6 \pm 10.1$ & $24.4 \pm 9.7$ & $37.5 \pm 8.2$ & $<0.001$ \\
Waist circumference $(\mathrm{cm})$ & $96.4 \pm 15.2$ & $104.3 \pm 13.9$ & $94.2 \pm 14.7$ & $<0.001$ \\
Waist/hip & $0.88 \pm 0.09$ & $0.96 \pm 0.09$ & $0.85 \pm 0.08$ & $<0.001$ \\
Waist/height & $0.59 \pm 0.09$ & $0.60 \pm 0.08$ & $0.59 \pm 0.10$ & 0.175 \\
Energy intake $(\mathrm{kcal})$ & $2,151 \pm 431$ & $2,477 \pm 464$ & $2,057 \pm 372$ & $<0.001$ \\
Physical activity & $1.23 \pm 0.03$ & $1.24 \pm 0.03$ & $1.23 \pm 0.03$ & 0.003
\end{tabular}

\begin{tabular}{|c|c|c|c|c|c|c|c|}
\hline Gene & SNP & $\begin{array}{l}\text { Major/ } \\
\text { minor } \\
\text { allele }^{\mathrm{a}}\end{array}$ & $\begin{array}{l}\text { Major allele } \\
\text { homozygote } \\
(\%)\end{array}$ & $\begin{array}{l}\text { Heterozygote } \\
(\%)\end{array}$ & $\begin{array}{l}\text { Minor allele } \\
\text { homozygote } \\
(\%)\end{array}$ & MAF & $\begin{array}{l}\text { HWE } \\
p \text { value }\end{array}$ \\
\hline FTO & rs9939609 & T/A & $218(30.6)$ & $351(49.4)$ & $142(20.0)$ & 0.45 & 0.973 \\
\hline$M C 4 R$ & rs 17782313 & $\mathrm{~T} / \mathrm{C}$ & $442(62.2)$ & $237(33.3)$ & $32(4.5)$ & 0.21 & 0.974 \\
\hline$M T H F R$ & rs1801133 & $\mathrm{C} / \mathrm{T}$ & $257(36.2)$ & $340(47.8)$ & $114(16.0)$ & 0.40 & 0.930 \\
\hline PPARA & rs 1800206 & $\mathrm{C} / \mathrm{G}$ & $591(83.1)$ & $116(16.3)$ & $3(0.5)$ & 0.09 & 0.507 \\
\hline PPARG & rs1801282 & $\mathrm{C} / \mathrm{G}$ & $594(82.5)$ & $110(15.5)$ & $7(1.0)$ & 0.09 & 0.453 \\
\hline APOA5 & rs662799 & $\mathrm{T} / \mathrm{C}$ & $620(87.2)$ & $88(12.4)$ & $3(0.4)$ & 0.07 & 0.948 \\
\hline$A P O E$ & rs429358 & $\mathrm{T} / \mathrm{C}$ & $574(80.7)$ & $129(18.1)$ & $8(1.1)$ & 0.10 & 0.804 \\
\hline$A P O E$ & rs 7412 & $\mathrm{C} / \mathrm{T}$ & $624(87.8)$ & 84 (11.8) & $3(0.4)$ & 0.06 & 0.923 \\
\hline$L I P C$ & rs1800588 & $\mathrm{C} / \mathrm{T}$ & $406(57.1)$ & $250(36.3)$ & 47 (6.6) & 0.24 & 0.489 \\
\hline PLIN1 & rs894160 & G/A & $378(53.2)$ & $282(39.7)$ & $51(7.2)$ & 0.27 & 0.872 \\
\hline NOS3 & rs 1799983 & $\mathrm{G} / \mathrm{T}$ & $286(40.2)$ & $326(45.8)$ & 99 (13.9) & 0.37 & 0.692 \\
\hline$G C K R$ & rs1260326 & $\mathrm{C} / \mathrm{T}$ & $208(29.2)$ & $367(50.9)$ & $141(19.8)$ & 0.45 & 0.465 \\
\hline$L P L$ & rs 328 & $\mathrm{C} / \mathrm{G}$ & $510(71.7)$ & 189 (26.6) & $12(1.7)$ & 0.15 & 0.244 \\
\hline CELSR2 & rs 12740374 & $\mathrm{G} / \mathrm{T}$ & 440 (61.9) & 241 (33.9) & $30(4.2)$ & 0.21 & 0.676 \\
\hline CETP & rs1800777 & G/A & $681(95.8)$ & $28(3.9)$ & $2(0.3)$ & 0.02 & 0.005 \\
\hline$L I P G$ & rs4939883 & $\mathrm{C} / \mathrm{T}$ & $508(71.4)$ & $179(25.2)$ & $24(3.4)$ & 0.16 & 0.100 \\
\hline
\end{tabular}

metabolic disorders: $22.2 \%$ hypertension, $3.2 \%$ type 2 diabetes, $28.0 \%$ different lipid metabolism impairments and $3.1 \%$ cardiovascular disease.

The minor allele frequencies (MAF) and Hardy-Weinberg Equilibrium for each SNP are listed (Table 2). MAF ranged from 0.02 to 0.45 in the population. The distributions of the all polymorphisms alleles were in HardyWeinberg Equilibrium $(p>0.05)$, except rs1800777 in CETP ( $p=0.0052)$. Moreover, risk alleles for each SNP and alleles frequencies in HapMap CEU population have been reported (Supplementary Material Table 1).

The association of each SNP of the GRS with obesityrelated traits including BMI, percentage of BFM, waist circumference, waist/hip and waist/height (after adjusted for age, gender, physical activity and energy intake) was analyzed (data not shown). Individuals with the genotype
AA of the rs9939609 genetic variant in the FTO gene had greater BMI, percentage of BFM, waist circumference and waist/height. The $\mathrm{C}$ allele carriers of the genetic variant rs429358 (APOE) showed significantly higher BMI, and a tendency was observed for the percentage of BFM, waist circumference and hip circumference. None of the other SNPs showed significant association with any other quantitative traits in the case of the total population. After adjusted for confounder variables, only rs9939609 (FTO) was significantly associated with obesity risk in the current study, while rs429358 (APOE) showed a trend toward significance (Supplementary Material Table 1).

The GRS, calculated as the number of risk alleles carried by each subject, was normally distributed. The average number of risk alleles per person was 8.09 ( $\mathrm{SD}=2.02)$, which ranged from 2 to 16 . The sample was stratified, by 
the median, into a "low genetic risk group," those with a GRS $\leq 7$ risk alleles $(n=289)$, and into a "high genetic risk group," those with a GRS $>7$ risk alleles $(n=422)$.

Results from linear regression and logistic regression analyses revealed that the group with a GRS of $>7$ risk alleles had a $0.93 \mathrm{~kg} / \mathrm{m}^{2}$ greater BMI, a 1.69 greater percentage of BFM, a $1.94 \mathrm{~cm}$ larger waist circumference and a greater 0.01 waist/height compared with the group with a GRS of $\leq 7$ risk alleles, after they were adjusted for age, gender, physical activity and energy intake (Table 3). It should be highlighted that when the GRS was considered as a continuous variable, the associations between BMI, waist circumference, waist/hip and waist/height ratios, and GRS were no longer statistically significant. However, a significant association was observed with the percentage of BFM when considered the GRS as a continuous variable (B coefficient $0.373,95 \% \mathrm{CI} \quad 0.10-0.64, p 0.007)$, after adjusted for the previously mentioned confounder variables. Individuals in the high genetic risk group, after confounder variables adjustment (age, gender, physical activity and energy intake), were at 42 and $72 \%$ greater risk of obesity according to BMI and percentage of BFM, respectively. The risk of cardiovascular disease, taking into account waist circumference, was $57 \%$ higher in the high genetic risk group than that in the low genetic risk group.

Moreover, the ROC curves for the prediction of obesity according to BMI and the percentage of BFM were calculated. The AUC estimates were low. The GRS predicted obesity with a maximum discriminating ability when the percentage of BFM was taken into account (AUC 0.55; $95 \%$ CI 0.51-0.60). The AUC was $0.53(95 \%$ CI 0.48-0.57) when the BMI was considered.

Significant SNPs' interactions (FTO, PPARG and $A P O E$ ) with some macronutrient intake that modified the association with BFM were detected (data not shown). After correction for multiple testing, interactions between $F T O$ and total fat $(p$ interaction $=0.016)$ and MUFA intake $(p$ interaction $=0.012), P P A R G$ and animal protein $(p$ interaction $=0.011)$ and diet cholesterol intake, ( $p$ interaction $=0.028)$ and $A P O E$ and complex carbohydrates intake $(p$ interaction $=0.027)$ on BFM remained significant.

After data were adjusted for gender, age, physical activity and energy intake, several macronutrients modified the effect of the GRS on percentage of BFM and risk of obesity (Table 4, Supplementary Material Fig. 1-4). A higher energy intake was associated with an increase of 0.39 (SE 0.04) percentage of BFM in the high genetic risk group, while the effect was much less in the low genetic risk group. Similar trends for interaction were found for protein $(p$ interaction $=0.003)$ and fat intakes $(p$ interaction $=0.029)$. Interestingly, when stratifying by animal and vegetable protein, the vegetable intake seemed to improve the percentage of the BFM ( $p$ interaction $=0.003$ ) in the $\leq 7$

Table 3 Linear regression coefficients and logistic regression coefficients for the association between GRS (dichotomized by the median) and several anthropometric variables

\begin{tabular}{|c|c|c|c|c|c|c|c|c|}
\hline & \multicolumn{4}{|c|}{ Linear regression coefficients } & \multicolumn{4}{|c|}{ Logistic regression coefficients } \\
\hline & \multicolumn{2}{|l|}{ Model 1} & \multicolumn{2}{|l|}{ Model 2} & \multicolumn{2}{|l|}{ Model 1} & \multicolumn{2}{|l|}{ Model 2} \\
\hline & $\mathrm{B}(95 \% \mathrm{CI})$ & $p$ value & $\mathrm{B}(95 \% \mathrm{CI})$ & $p$ value & OR $(95 \% \mathrm{CI})$ & $p$ value & OR $(95 \% \mathrm{CI})$ & $p$ value \\
\hline \multicolumn{9}{|l|}{ BMI $\left(\mathrm{kg} / \mathrm{m}^{2}\right)$} \\
\hline$\leq 7$ risk alleles & 0 (ref.) & & 0 (ref.) & & 1 (ref.) & & 1 (ref.) & \\
\hline$>7$ risk alleles & $1.02(0.17-1.87)$ & 0.019 & $0.93(0.17-1.68)$ & 0.016 & $1.41(1.04-1.93)$ & 0.031 & $1.42(1.02-1.99)$ & 0.038 \\
\hline \multicolumn{9}{|c|}{ Percentage of BFM } \\
\hline$\leq 7$ risk alleles & 0 (ref.) & & 0 (ref.) & & 1 (ref.) & & 1 (ref.) & \\
\hline$>7$ risk alleles & $1.81(0.59-3.03)$ & 0.004 & $1.69(0.58-2.80)$ & 0.003 & $1.72(1.22-2.42)$ & 0.002 & $1.72(1.19-2.48)$ & 0.004 \\
\hline \multicolumn{9}{|c|}{ Waist circumference $(\mathrm{cm})$} \\
\hline$\leq 7$ risk alleles & 0 (ref.) & & 0 (ref.) & & 1 (ref.) & & 1 (ref.) & \\
\hline$>7$ risk alleles & $2.14(0.08-4.21)$ & 0.042 & $1.94(0.12-3.75)$ & 0.036 & $1.54(1.04-2.29)$ & 0.032 & $1.57(1.02-2.40)$ & 0.039 \\
\hline \multicolumn{9}{|l|}{ Waist-to-hip ratio } \\
\hline$\leq 7$ risk alleles & 0 (ref.) & & 0 (ref.) & & 1 (ref.) & & 1 (ref.) & \\
\hline$>7$ risk alleles & $0.00(-0.01-0.002)$ & 0.445 & $0.00(-0.01-0.01)$ & 0.480 & $1.15(0.82-1.61)$ & 0.401 & $1.14(0.81-1.61)$ & 0.454 \\
\hline \multicolumn{9}{|c|}{ Waist-to-height ratio } \\
\hline$\leq 7$ risk alleles & 0 (ref.) & & 0 (ref.) & & 1 (ref.) & & 1 (ref.) & \\
\hline$>7$ risk alleles & $0.01(0.00-0.03)$ & 0.036 & $0.01(0.00-0.02)$ & 0.029 & $1.39(0.95-2.02)$ & 0.089 & $1.41(0.94-2.10)$ & 0.096 \\
\hline
\end{tabular}

Model 1: Adjusted for gender and age

Model 2: Adjusted for gender, age, physical activity and energy intake

$B M I$ body mass index, BMF body fat mass, $95 \%$ CI $95 \%$ confidence interval, OR odds ratio 
Table 4 The dietary intake modifies the GRS association with BFM (\%) and the obesity risk (as \% of BFM)

\begin{tabular}{|c|c|c|c|c|c|c|}
\hline & $\beta(\mathrm{SE})$ & $p$ value & $p$ value for interaction & OR $(95 \% \mathrm{CI})$ & $p$ value & $p$ value for interaction \\
\hline \multicolumn{7}{|c|}{ Energy intake (kcal) } \\
\hline$\leq 7$ risk alleles & $0.17(0.05)$ & $<0.001$ & & $1.00(1.00-1.00)$ & 0.041 & \\
\hline$>7$ risk alleles & $0.39(0.04)$ & $<0.001$ & $0.002 *$ & $1.00(1.00-1.00)$ & $<0.001$ & $<0.001 *$ \\
\hline \multicolumn{7}{|l|}{ Total protein $(\mathrm{g})$} \\
\hline$\leq 7$ risk alleles & $0.11(0.06)$ & 0.060 & & $1.01(0.99-1.02)$ & 0.302 & \\
\hline$>7$ risk alleles & $0.20(0.04)$ & $<0.001$ & $0.003 *$ & $1.02(1.00-1.03)$ & 0.037 & $0.001 *$ \\
\hline \multicolumn{7}{|c|}{ Animal protein $(\mathrm{g})$} \\
\hline$\leq 7$ risk alleles & $0.09(0.05)$ & 0.053 & & $1.01(0.99-1.02)$ & 0.261 & \\
\hline$>7$ risk alleles & $0.13(0.04)$ & 0.002 & 0.032 & $1.01(1.00-1.03)$ & 0.080 & $0.021^{*}$ \\
\hline \multicolumn{7}{|c|}{ Vegetable protein $(\mathrm{g})$} \\
\hline$\leq 7$ risk alleles & $-0.06(0.06)$ & 0.340 & & $0.98(0.94-1.03)$ & 0.484 & \\
\hline$>7$ risk alleles & $0.02(0.06)$ & 0.730 & $0.003 *$ & $1.01(0.96-1.06)$ & 0.657 & $0.001 *$ \\
\hline \multicolumn{7}{|l|}{ Total fat (g) } \\
\hline$\leq 7$ risk alleles & $0.05(0.05)$ & 0.349 & & $1.01(0.99-1.02)$ & 0.326 & \\
\hline$>7$ risk alleles & $0.07(0.05)$ & 0.179 & 0.029 & $1.01(0.99-1.02)$ & 0.324 & $0.017 *$ \\
\hline \multicolumn{7}{|l|}{ SFA (g) } \\
\hline$\leq 7$ risk alleles & $-0.00(0.06)$ & 0.938 & & $1.00(0.93-1.07)$ & 0.945 & \\
\hline$>7$ risk alleles & $0.03(0.05)$ & 0.537 & $0.015^{*}$ & $0.99(0.93-1.05)$ & 0.810 & $0.017 *$ \\
\hline \multicolumn{7}{|l|}{ MUFA (g) } \\
\hline$\leq 7$ risk alleles & $0.07(0.05)$ & 0.139 & & $1.02(0.99-1.05)$ & 0.144 & \\
\hline$>7$ risk alleles & $0.07(0.04)$ & 0.123 & 0.121 & $1.02(0.99-1.04)$ & 0.177 & 0.082 \\
\hline \multicolumn{7}{|l|}{ PUFA (g) } \\
\hline$\leq 7$ risk alleles & $-0.05(0.06)$ & 0.388 & & $0.96(0.87-1.05)$ & 0.365 & \\
\hline$>7$ risk alleles & $0.04(0.05)$ & 0.396 & $0.002 *$ & $1.06(0.95-1.18)$ & 0.279 & $0.004 *$ \\
\hline \multicolumn{7}{|c|}{ Diet cholesterol (mg) } \\
\hline$\leq 7$ risk alleles & $0.09(0.05)$ & 0.061 & & $1.00(1.00-1.00)$ & 0.492 & \\
\hline$>7$ risk alleles & $0.06(0.04)$ & 0.163 & 0.309 & $1.00(1.00-1.00)$ & 0.492 & 0.090 \\
\hline \multicolumn{7}{|c|}{ Total carbohydrates (g) } \\
\hline$\leq 7$ risk alleles & $-0.03(0.05)$ & 0.638 & & $1.00(0.99-1.00)$ & 0.461 & \\
\hline$>7$ risk alleles & $0.05(0.05)$ & 0.318 & $0.008 *$ & $1.00(1.00-1.01)$ & 0.402 & $0.001 *$ \\
\hline \multicolumn{7}{|c|}{ Simple carbohydrates (g) } \\
\hline$\leq 7$ risk alleles & $-0.17(0.05)$ & $<0.001$ & & $0.99(0.98-1.00)$ & 0.005 & \\
\hline$>7$ risk alleles & $-0.16(0.04)$ & $<0.001$ & 0.270 & $0.97(0.96-0.98)$ & $<0.001$ & 0.997 \\
\hline \multicolumn{7}{|c|}{ Complex carbohydrates $(\mathrm{g})$} \\
\hline$\leq 7$ risk alleles & $0.05(0.05)$ & 0.387 & & $1.00(0.99-1.01)$ & 0.559 & \\
\hline$>7$ risk alleles & $0.08(0.05)$ & 0.153 & 0.030 & $1.01(1.00-1.01)$ & 0.049 & $0.001 *$ \\
\hline \multicolumn{7}{|l|}{ Fiber $(\mathrm{g})$} \\
\hline$\leq 7$ risk alleles & $-0.09(0.05)$ & 0.101 & & $0.97(0.93-1.01)$ & 0.188 & \\
\hline$>7$ risk alleles & $-0.06(0.05)$ & 0.245 & 0.039 & $0.96(0.92-1.00)$ & 0.048 & 0.059 \\
\hline
\end{tabular}

Adjusted for gender, age, physical activity and energy intake

SFA saturated fatty acids, MUFA monounsaturated fatty acids, PUFA polyunsaturated fatty acids, SE standard error, $95 \%$ CI $95 \%$ confidence interval

* $p$ value $<0.05$ Benjamini-Hochberg correction for multiple comparisons

risk alleles group, whereas the animal protein intake was associated with an increase in the percentage of BFM in the $>7$ risk alleles group $(p$ interaction $=0.032$ ). Moreover, the higher the increase in AGS ( $p$ interaction $=0.015$ ), carbohydrates $(p$ interaction $=0.008)$ and complex carbohydrates
( $p$ interaction $=0.030$ ), the higher the percentage of BFM in the high genetic risk group. In contrast, the higher the intake of AGP ( $p$ interaction $=0.002$ ) and fiber ( $p$ interaction $=0.039$ ), the lower the percentage of BFM in the low genetic risk group. The same tendency was observed in 
those analyses taking into account the risk of obesity as the percentage of BFM (Table 4). Similar results were evidenced regarding interactions between dietary intakes and GRS, by dichotomizing macronutrients according to the mean population intakes and evaluating their effects on the percentage of BFM as continuous and categorical variable (adjusted for age, gender, physical activity and energy intake) (data not shown).

\section{Discussion}

In this cross-sectional study encompassing 711 users of a Nutrigenetic Service, it was investigated the predictive value of 16 obesity and lipid metabolism risk polymorphisms in the adiposity outcome and the possible modifying effect of the dietary intake. Our study shows that after combining information of 16 polymorphisms, those people who were classified as high genetic risk group presented higher values in obesity-related traits and a higher risk of obesity than the alternative group. In addition, the consumption of some specific macronutrients modified the association between the GRS and BFM and obesity risk. Interestingly, this is apparently the first study analyzing whether macronutrient intake can modulate the association between a multi-trait GRS and obesity.

When looking at single SNPs' results, in agreement with previous investigations, the current study reported a significant association between rs9939609 (FTO) and BMI, BFM and measures of central obesity (waist circumference and waist/height ratio) (Fall and Ingelsson 2014). Recently, it has been published that FTO is functionally connected with the regulation of $I R X 3$ expression, which is involved in body composition (Smemo et al. 2014). Although the relationship between $F T O$ and obesity-related traits has been confirmed in several populations, in Spanish individuals, there is a little controversy (Fall and Ingelsson 2014). One study investigated the contribution of FTO, among other several polymorphisms, to obesity in two Spanish cohorts (Martinez-Garcia et al. 2013). Whereas FTO was associated with BMI in the Pizarra cohort, this result was not found in the Hortega cohort (MartinezGarcia et al. 2013). In addition to the well-described rs9939609 (FTO), the polymorphism rs429358 located in $A P O E$ showed a statistically significant association with BMI in the present study. APOE gene encodes for a major structural apolipoprotein of several lipoprotein classes (chylomicrons, very low-density lipoprotein-VLDL-and HDL), which plays diverse roles in lipoprotein metabolism. Polymorphisms in APOE have been previously related with lipid metabolism disorders, cardiovascular disease, Alzheimer's disease and obesity phenotype (Sima et al. 2007; Kypreos et al. 2009; Ridge et al. 2013). Although a large number of studies have observed the association between $A P O E$ genotypes and obesity, up to date, no study has found any statistically significant association between rs429358 and obesity phenotype (Clark et al. 2009). A number of studies in vitro and in vivo have explained the link between $A P O E$ and obesity, due to the contribution of $A P O E$ in adipogenesis (Kypreos et al. 2009).

A weighted GRS, computed by weighting each variant by their effect size, can be used. However, we selected a simple count method because weighted models may have only limited effects, as has been reported by some previous studies (Belsky et al. 2013; Cheung et al. 2010). Moreover, the effect sized on obesity for some of the selected SNPs is not established. The GRS design was based on the premise that some of the loci reliably associated with obesity-related traits, such as lipid metabolism disorders, might increase the power to discriminate between individuals with and without obesity. Although the polymorphism rs1800777 (CETP) was not in Hardy-Weinberg Equilibrium, it was included in the GRS because it was associated with the percentage of BFM in males and females.

The GRS was positively associated with several measures of obesity in our study population. In this regard, it should be noted that from a clinical point of view, the categorization of a genetic score into a dichotomous variable could be more useful for clinical decision making (Horne et al. 2005). The analyses demonstrated that the GRS as a continuous variable predicts $<1 \%$ of the BMI variation $(0.16 \%)$ in concordance with most of previous studies (Li et al. 2010a; Takeuchi et al. 2011; Peterson et al. 2011; Lemas et al. 2013). Nevertheless, our GRS explained 1.59\%. Although BMI has been widely used as a surrogate measure of adiposity, it does not distinguish between BFM and lean mass. So, the accuracy of BMI in assessing the BFI remains debated, and the measurement of BFM is a more specific measure of adiposity than BMI, which can explain our findings (Bergman et al. 2011).

Additionally, ROC curves and the corresponding AUC estimates indicated statistical discriminative ability to predict obesity taking into account both, BMI and the percentage of BFM. The discriminatory ability of our GRS was similar when compared to other obesity GRS, which ranged between 0.575 and 0.697 (Renstrom et al. 2009; Cheung et al. 2010; Li et al. 2010b; Peterson et al. 2011; Belsky et al. 2013).

Our data show that high energy intake was associated with higher percentage of BFM in the population overall, but that in particular individuals of the high genetic risk group, the effect on adiposity of a high energy intake was stronger. So, all of the likelihood ratio analyses were adjusted for energy intake. 
Currently, the beneficial effect of the consumption of proteins is debated, mainly in relation with the protein source (Lopez-Legarrea et al. 2014). Higher total protein and animal protein intake were significantly associated with higher BFM in both genetic risk groups, but this association was significantly stronger among individuals of the high genetic risk group. Meanwhile, vegetable protein intake appears to have a protective effect among individuals of the low genetic risk group. Previously, (Rukh et al. 2013) found that protein intake modulates the association between a 13 polymorphisms' GRS and obesity and fat mass in Swedish women. Also a gene-diet interaction between PPARG and total protein and animal protein intake was observed in BFM. In this sense, other investigations have previously reported the PPARG interaction with total fat, MUFA and carbohydrate intake in obesityrelated traits (Robitaille et al. 2003; Dedoussis et al. 2011; Garaulet et al. 2011; Galbete et al. 2013b).

Although the association between total fat and SFA intake and obesity is well studied, this is the first investigation confirming the combined effect of these nutrients and GRS on adiposity (Cascio et al. 2012). In this context, Qi et al. (2014) reported that among individuals with a higher GRS, the association between fried food consumption and BMI was stronger than that among individuals with a lower GRS. Our study also suggests that PUFA intake could modify the genetic association with body composition. This is in accordance with findings from a previous study which detected a significant interaction between a 12 obesity SNPs' GRS and omega-3 PUFA and BMI (Lemas et al. 2013). In addition to the interaction with GRS, several nominal interactions with FTO and dietary fat were found; thus, FTO interacted with total fat and MUFA intake to modify its effect on BFM. Earlier studies have also reported $F T O$-diet interactions on obesity-related traits (Sonestedt et al. 2009; Ahmad et al. 2011; Lappalainen et al. 2012; Phillips et al. 2012).

Another novel finding of our study is that total carbohydrates and complex carbohydrates interacted with the GRS to modify the effect on BFM. There are no previous reports regarding these interactions, but Qi et al. (2012b) found an interaction between sugar-sweetened beverages and a GRS of 32 obesity polymorphisms in three US cohort studies. Finally, an interaction between the polymorphism rs7412 (APOE) and complex carbohydrates was found.

The major strength of the present study is the use of a population who attended voluntarily a Nutrigenetic Service. As far as we know, this is the first study that analyzes a real population of a nutritional service based on the genetic makeup. Moreover, we used a bioimpedance technique to evaluate body composition instead of BMI or other anthropometric measurements, as many studies do.
Nevertheless, some limitations need to be acknowledged. The users included in the study were middle aged and of European ancestry, so it is unknown whether our results can be generalized to other demographic or ethnic groups. It is possible that the sample size might be rather relatively small; however, consistent GRS-environment interactions were found. Furthermore, the 16 selected SNPs may be only markers of functional variations and that future GWAS data will contribute to a better understanding of the genetic background of this population.

In conclusion, this study provides interesting novel information on obesity and lipid metabolism-related genes, their additive effects on the risk of obesity, and the modulation by dietary habits. The investigation of GRS-diet interactions may facilitate the selection of more individualized effective nutritional therapy, following personalized approaches based on the genotype.

Acknowledgments The authors thank all the users of the Nutrigenetic Service who voluntarily offer her data to the study. The authors are grateful to the five nutritionists for data collection and to Amaia Ibañez for excellent technical assistance. The predoctoral research grant to Leticia Goni from the Asociación de Amigos Universidad de Navarra is gratefully acknowledged. The authors also wish to thank the Linea Especial (University of Navarra; LE/97) for financial support and also CIBERobn/RETICS schedules (Instituto Carlos III) for assistance in this study. The support from CINFA concerning the genetic tools and general logistic is also gratefully acknowledged.

Conflict of interest The authors declare no financial conflict of interest concerning this research. However, there are some results of this work that could be incorporated to the future development of new nutrigenetic tests.

Ethical standard All procedures were in accordance with the Helsinki declaration 1975, as revised in 2010. Informed consent was obtained from all patients before for being included in the study.

\section{References}

Abete I, Astrup A, Martinez JA, Thorsdottir I, Zulet MA (2010) Obesity and the metabolic syndrome: role of different dietary macronutrient distribution patterns and specific nutritional components on weight loss and maintenance. Nutr Rev 68:214-231

Ahmad T, Lee IM, Pare G, Chasman DI, Rose L, Ridker PM, Mora S (2011) Lifestyle interaction with fat mass and obesity-associated (FTO) genotype and risk of obesity in apparently healthy U.S. women. Diabetes Care 34:675-680

Ahmad S, Rukh G, Varga TV et al (2013) Gene x physical activity interactions in obesity: combined analysis of 111,421 individuals of European ancestry. PLoS Genet 9:e1003607

Belsky DW, Moffitt TE, Sugden K, Williams B, Houts R, McCarthy J, Caspi A (2013) Development and evaluation of a genetic risk score for obesity. Biodemography Soc Biol 59:85-100

Bennet AM, Di Angelantonio E, Ye Z et al (2007) Association of Apolipoprotein E genotypes with lipid levels and coronary risk. JAMA 298:1300-1311 
Bergman RN, Stefanovski D, Buchanan TA, Sumner AE, Reynolds JC, Sebring NG, Xiang AH, Watanabe RM (2011) A better index of body adiposity. Obesity 19:1083-1089

Cascio G, Schiera G, Di Liegro I (2012) Dietary fatty acids in metabolic syndrome, diabetes and cardiovascular diseases. Curr Diabetes Rev 8:2-17

Cheung CY, Tso AW, Cheung BM, Xu A, Ong KL, Fong CH, Wat NM, Janus ED, Sham PC, Lam KS (2010) Obesity susceptibility genetic variants identified from recent genome-wide association studies: implications in a Chinese population. J Clin Endocrinol Metab 95:1395-1403

Chrysohoou C, Panagiotakos DB, Pitsavos C, Antoniades C, Skoumas J, Brown M, Stefanadis C (2004) Evidence for association between endothelial nitric oxide synthase gene polymorphism (G894T) and inflammatory markers: the ATTICA study. Am Heart J 148:733-738

Clark D, Skrobot OA, Adebiyi I, Susce MT, de Leon J, Blakemore AF, Arranz MJ (2009) Apolipoprotein-E gene variants associated with cardiovascular risk factors in antipsychotic recipients. Eur Psychiatry 24:456-463

Cleves M (1999) Receiver operating characteristic (ROC) analysis. Stata Tech Bull STB 52:19-31

de la Iglesia R, Lopez-Legarrea P, Abete I, Bondia-Pons I, NavasCarretero S, Forga L, Martinez JA, Zulet MA (2014) A new dietary strategy for long-term treatment of the metabolic syndrome is compared with the American Heart Association (AHA) Guidelines: the MEtabolic Syndrome REduction in NAvarra (RESMENA) project. Br J Nut 111:643-652

Dedoussis GV, Manios Y, Kourlaba G et al (2011) An age-dependent diet-modified effect of the PPARgamma Pro12Ala polymorphism in children. Metabolism 60:467-473

Dorfman DD, Alf E Jr (1969) Maximum-likelihood estimation of parameters of signal-detection theory and determination of confidence intervals-rating method data. J Math Psychol 6:487-496

Dunbar SA (2006) Applications of Luminex xMAP technology for rapid, high-throughput multiplexed nucleic acid detection. Clin Chim Acta 363:71-82

Fall T, Ingelsson E (2014) Genome-wide association studies of obesity and metabolic syndrome. Mol Cell Endocrinol 382:740-757

Ferguson JF, Phillips CM, McMonagle J et al (2010) NOS3 gene polymorphisms are associated with risk markers of cardiovascular disease, and interact with omega-3 polyunsaturated fatty acids. Atherosclerosis 211:539-544

Frayling TM, Timpson NJ, Weedon MN et al (2007) A common variant in the FTO gene is associated with body mass index and predisposes to childhood and adult obesity. Science 316:889-894

Galbete C, Toledo E, Martinez-Gonzalez MA, Martinez JA, GuillenGrima F, Marti A (2013a) Pro12Ala variant of the PPARG2 gene increases body mass index: an updated meta-analysis encompassing 49,092 subjects. Obesity 21:1486-1495

Galbete C, Toledo J, Martinez-Gonzalez MA, Martinez JA, GuillenGrima F, Marti A (2013b) Lifestyle factors modify obesity risk linked to PPARG2 and FTO variants in an elderly population: a cross-sectional analysis in the SUN project. Genes Nutr 8:61-67

Garaulet M, Smith CE, Hernandez-Gonzalez T, Lee YC, Ordovas JM (2011) PPARgamma Pro12Ala interacts with fat Intake for obesity and weight loss in a behavioural treatment based on the mediterranean diet. Mol Nutr Food Res 55:1771-1779

Global Lipids Genetics Consortium, Willer CJ, Schmidt EM et al (2013) Discovery and refinement of loci associated with lipid levels. Nat Genet 45:1274-1283

He M, Cornelis MC, Franks PW, Zhang C, Hu FB, Qi L (2010) Obesity genotype score and cardiovascular risk in women with type 2 diabetes mellitus. Arterioscler Thromb Vasc Biol 30:327-332
Horne BD, Anderson JL, Carlquist JF, Muhlestein JB, Renlund DG, Bair TL, Pearson RR, Camp NJ (2005) Generating genetic risk scores from intermediate phenotypes for use in association studies of clinically significant endpoints. Ann Hum Genet 69:176-186

Jaaskelainen A, Schwab U, Kolehmainen M, Kaakinen M, Savolainen MJ, Froguel P, Cauchi S, Jarvelin MR, Laitinen J (2013) Meal frequencies modify the effect of common genetic variants on body mass index in adolescents of the Northern Finland Birth Cohort 1986. PLoS ONE 8:e73802

Kathiresan S, Melander O, Guiducci C et al (2008) Six new loci associated with blood low-density lipoprotein cholesterol, highdensity lipoprotein cholesterol or triglycerides in humans. Nat Genet 40:189-197

Kelly T, Yang W, Chen CS, Reynolds K, He J (2008) Global burden of obesity in 2005 and projections to 2030. Int J Obes 32:1431-1437

Kettunen J, Tukiainen T, Sarin AP et al (2012) Genome-wide association study identifies multiple loci influencing human serum metabolite levels. Nat Genet 44:269-276

Kypreos KE, Karagiannides I, Fotiadou EH, Karavia EA, Brinkmeier MS, Giakoumi SM, Tsompanidi EM (2009) Mechanisms of obesity and related pathologies: role of Apolipoprotein $\mathrm{E}$ in the development of obesity. FEBS J 276:5720-5728

Lappalainen T, Lindstrom J, Paananen J, Eriksson JG, Karhunen L, Tuomilehto J, Uusitupa M (2012) Association of the fat mass and obesity-associated (FTO) gene variant (rs9939609) with dietary intake in the Finnish Diabetes Prevention Study. Br J Nut 108:1859-1865

Lemas DJ, Klimentidis YC, Wiener HH, O’Brien DM, Hopkins SE, Allison DB, Fernandez JR, Tiwari HK, Boyer BB (2013) Obesity polymorphisms identified in genome-wide association studies interact with n-3 polyunsaturated fatty acid intake and modify the genetic association with adiposity phenotypes in Yup'Ik people. Genes Nutr 8:495-505

Lewis SJ, Lawlor DA, Nordestgaard BG, Tybjaerg-Hansen A, Ebrahim S, Zacho J, Ness A, Leary S, Smith GD (2008) The methylenetetrahydrofolate reductase C677T genotype and the risk of obesity in three large population-based cohorts. Eur J Endocrinol 159:35-40

Li S, Zhao JH, Luan J, Ekelund U, Luben RN, Khaw KT, Wareham NJ, Loos RJ (2010a) Physical activity attenuates the genetic predisposition to obesity in 20,000 men and women from EPICNorfolk prospective population study. PLoS Med 7(10):1371

Li S, Zhao JH, Luan J, Luben RN, Rodwell SA, Khaw KT, Ong KK, Wareham NJ, Loos RJ (2010b) Cumulative effects and predictive value of common obesity-susceptibility variants identified by genome-wide association studies. Am J Clin Nutr 91:184-190

Lind JM, Chiu CL (2013) Genetic discoveries in hypertension: steps on the road to therapeutic translation. Heart 99:1645-1651

Loos RJ, Lindgren CM, Li S et al (2008) Common variants near MC4R are associated with fat mass, weight and risk of obesity. Nat Genet 40:768-775

Lopez-Legarrea P, de la Iglesia R, Abete I, Navas-Carretero S, Martinez JA, Zulet MA (2014) The protein type within a hypocaloric diet affects obesity-related inflammation: the RESMENA project. Nutrition 30:424-429

Lu Y, Dolle ME, Imholz S, van't Slot R, Verschuren WM, Wijmenga C, Feskens EJ, Boer JM (2008) Multiple genetic variants along candidate pathways influence plasma high-density lipoprotein cholesterol concentrations. J Lipid Res 49:2582-2589

Martinez-Garcia F, Mansego ML, Rojo-Martinez G et al (2013) Impact of obesity-related genes in Spanish population. BMC Genet 14:111

Mataix J, García L, Mañas M, Martínez E, Llopis J (2009) Tablas de composición de alimentos, 5th edn. Universidad de Granada, Granada 
Min J, Chiu DT, Wang Y (2013) Variation in the heritability of body mass index based on diverse twin studies: a systematic review. Obes Rev 14:871-882

Moonesinghe R, Liu T, Khoury MJ (2010) Evaluation of the discriminative accuracy of genomic profiling in the prediction of common complex diseases. Eur J Hum Genet 18:485-489

Moreira O, Carbajal A, Cabrera L, Cuadrado C (2012) Tablas de composición de alimentos, 15th edn. Pirámide, Madrid

Panel on Macronutrients, Panel on the Definition of Dietary Fiber, Subcommittee on Upper Reference Levels of Nutrients, Subcommittee on Interpretation and Uses of Dietary Reference Intakes, and the Standing Committee on the Scientific Evaluation of Dietary Reference Intakes (2005) Dietary reference intakes for energy, carbohydrate, fiber, fat, fatty acids, cholesterol, protein, and amino acids (Macronutrients). The National Academies Press, Washington

Peterson RE, Maes HH, Holmans P, Sanders AR, Levinson DF, Shi J, Kendler KS, Gejman PV, Webb BT (2011) Genetic risk sum score comprised of common polygenic variation is associated with body mass index. Hum Genet 129:221-230

Phillips CM, Kesse-Guyot E, McManus R, Hercberg S, Lairon D, Planells R, Roche HM (2012) High dietary saturated fat intake accentuates obesity risk associated with the fat mass and obesityassociated gene in adults. J Nutr 142:824-831

Qi L (2014) Gene-diet interaction and weight loss. Curr Opin Lipidol 25:27-34

Qi Q, Hu FB (2012) Genetics of type 2 diabetes in European populations. J Diabetes 4:203-212

Qi Q, Chu AY, Kang JH et al (2012a) Sugar-sweetened beverages and genetic risk of obesity. N Engl J Med 367:1387-1396

Qi Q, Li Y, Chomistek AK, Kang JH, Curhan GC, Pasquale LR, Willett WC, Rimm EB, Hu FB, Qi L (2012b) Television watching, leisure time physical activity, and the genetic predisposition in relation to body mass index in women and men. Circulation 126:1821-1827

Qi Q, Chu AY, Kang JH et al (2014) Fried food consumption, genetic risk, and body mass index: gene-diet interaction analysis in three US cohort studies. BMJ 348:g1610

Razquin C, Marti A, Martinez JA (2011) Evidences on three relevant obesogenes: mC4R, FTO and PPARgamma. Approaches for personalized nutrition. Mol Nutr Food Res 55:136-149

Renstrom F, Payne F, Nordstrom A, Brito EC, Rolandsson O, Hallmans G, Barroso I, Nordstrom P, Franks PW, GIANT Consortium (2009) Replication and extension of genome-wide association study results for obesity in 4923 adults from Northern Sweden. Hum Mol Genet 18:1489-1496

Ridge PG, Ebbert MT, Kauwe JS (2013) Genetics of Alzheimer's disease. Biomed Res Int 2013:254954

Robitaille J, Despres JP, Perusse L, Vohl MC (2003) The PPARgamma P12A Polymorphism modulates the relationship between dietary fat intake and components of the metabolic syndrome: results from the Quebec Family Study. Clin Genet 63:109-116

Roth SM, Rankinen T, Hagberg JM, Loos RJ, Perusse L, Sarzynski MA, Wolfarth B, Bouchard C (2012) Advances in exercise, fitness, and performance genomics in 2011. Med Sci Sports Exerc 44:809-817

Rubio MA, Salas-Salvadó J, Barbany M et al (2007) Consenso SEEDO 2007 para la evaluación del sobrepeso y la obesidad y el establecimiento de criterios de intervención terapéutica. Rev Esp Obes 5(3):7-48

Rukh G, Sonestedt E, Melander O, Hedblad B, Wirfalt E, Ericson U, Orho-Melander M (2013) Genetic susceptibility to obesity and diet intakes: association and interaction analyses in the Malmo Diet and Cancer Study. Genes Nutr 8:535-547

Sánchez-Villegas A, Martínez-Gonzalez MA (2006) Aspectos avanzados de regresión múltiple. In: Martínez-González MA, Sánchez-Villegas A, Faulin J (eds) Bioestadística Amigable, 2nd edn. Diaz de Santos, España, pp 761-765

San-Cristobal R, Milagro FI, Martinez JA (2013) Future challenges and present ethical considerations in the use of personalized nutrition based on genetic advice. J Acad Nutr Diet 113:1447-1454

Sandhu MS, Waterworth DM, Debenham SL et al (2008) LDLcholesterol concentrations: a genome-wide association study. Lancet 371:483-491

Sima A, Iordan A, Stancu C (2007) Apolipoprotein E polymorphism-a risk factor for metabolic syndrome. Clin Chem Lab Med 45:1149-1153

Smemo S, Tena JJ, Kim KH et al (2014) Obesity-associated variants within FTO form long-range functional connections with IRX3. Nature 507:371-375

Sociedad Española para el Estudio de la Obesidad (SEEDO) (2000) Consenso SEEDO'2000 para la evaluación del sobrepeso y obesidad y el establecimiento de criterios de intervención quirúrgica. Med Clin 115:587-597

Soenen S, Mariman EC, Vogels N, Bouwman FG, den Hoed M, Brown L, Westerterp-Plantenga MS (2009) Relationship between Perilipin gene polymorphisms and body weight and body composition during weight loss and weight maintenance. Physiol Behav 96:723-728

Sonestedt E, Roos C, Gullberg B, Ericson U, Wirfalt E, OrhoMelander M (2009) Fat and carbohydrate intake modify the association between genetic variation in the FTO genotype and obesity. Am J Clin Nutr 90:1418-1425

Tai ES, Demissie S, Cupples LA, Corella D, Wilson PW, Schaefer WJ, Ordovas JM (2002) Association between the PPARA L162V polymorphism and plasma lipid levels: the Framingham Offspring Study. Arterioscler Thromb Vasc Biol 22:805-810

Takeuchi F, Yamamoto K, Katsuya T et al (2011) Association of genetic variants for susceptibility to obesity with type 2 diabetes in Japanese individuals. Diabetologia 54:1350-1359

Wang YC, McPherson K, Marsh T, Gortmaker SL, Brown M (2011) Health and economic burden of the projected obesity trends in the USA and the UK. Lancet 378:815-825

Willer CJ, Sanna S, Jackson AU et al (2008) Newly identified loci that influence lipid concentrations and risk of coronary artery disease. Nat Genet 40:161-169

Willer CJ, Speliotes EK, Loos RJ, Li S et al (2009) Six new loci associated with body mass index highlight a neuronal influence on body weight regulation. Nat Genet 41:25-34

World Health Organization (2008) Waist circumference and waisthip ratio: report of a WHO expert consultation, Geneva

World Medical Association (2013) World Medical Association Declaration of Helsinki: ethical principles for medical research involving human subjects. JAMA 31:2191-2194 